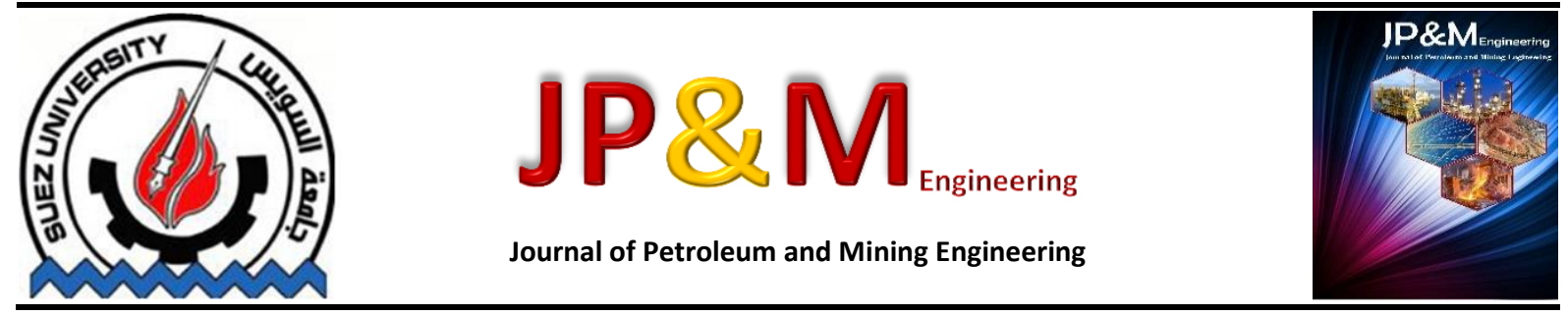

\title{
Study of the Corrosion Products Formed on Low-Carbon Steel Exposed to Different Environments in Egypt
}

\author{
S.S. Abd-Elmomen* \\ Dept.of Metallurgy, Tabbin institute for metallurgical studies, Tabbin, Egypt
}

\section{Keywords \\ Carbon steel; Industrial; Urban; Coastal; Atmospheric corrosion.}

\begin{abstract}
The corrosion performance of carbon steel X52 was studied after exposure up to 12 months in three atmospheric environments in Egypt. The results are in agreement with kinetic equations of the form $P=A t B$, where $P$ is the corrosion penetration, $t$ is time, and $A$, and $B$ are constants. The corrosion resistance of carbon steel, especially in industrial and urban sites are better than in coastal site. The corrosion products were characterized by XRD and SEM.
\end{abstract}

\section{Introduction}

Steel is used for making a wide range of equipment and metallic structures due to its low cost and high mechanical strength. Manufactured steel is usually exposed to outdoor conditions; often in highly polluted atmospheres where corrosion is considerably more severe than in clean rural environments. Carbon steel is an alloy of wide applications along the human civilization. The atmospheric corrosion of carbon steel has always been of prime interest for electrochemists and corrosion engineers because as it is the most widely spread corrosion process found in nature. Leading to the destruction of the materials, shaping the industrial age and is therefore responsible for immense financial loss. The corrosion products which form on carbon steel are influenced by the environmental condition, such as temperature, relative humidity, and the presence of atmospheric constituents such as $\mathrm{SO} 2$ and chlorides [1-4]. Many researchers have studied the corrosion products formed on carbon steels exposed to various atmospheres [5-8]. The main corrosion products on the surface of steel reported are mainly $\gamma$ $-\mathrm{FeOOH}$ (lepidocrocite), $\alpha$ - $\mathrm{FeOOH}$ (goethite), $\mathrm{Fe}_{3} \mathrm{O}_{4}$ (magnetite), and $-\gamma-\mathrm{Fe}_{2} \mathrm{O}_{3}$ [9-10]. These products can coexist partly as crystalline and partly as amorphous structures, the relative amounts of which will vary depending on the environmental conditions. The rust layer formed on carbon steel is generally porous, with poor adherence, and cracked in its outer part. This structure gives a poor protection to steel against atmospheric corrosion, because it is not a barrier to the passage of electrolyte and corrosive species towards the metallic substrate [1, 11-12]. In the present work, SEM/EDX and XRD were used to characterize the corrosion products formed on carbon steel when exposed to various environments in Egypt.

\section{Experimental work}

\section{Exposure tests}

The material examined was used for the field test carbon steel plates with the dimensions $100 \mathrm{~mm} * 150 \mathrm{~mm} * 3 \mathrm{~mm}$. Table 1 gives the analysis of this steel obtained from the Egyptian Iron and Steel Company(EISCO). Surface preparation of steel plates consisted of mechanical grinding with 800 grade silicon carbide paper, cleaning and then dried. Immediately before testing, they were weighed on analytical balance of $0.01 \mathrm{~g}$ sensitivity. According to ASTM G 50-76 [13], specification the test panels were exposed at 300 to the horizontal, with skyward surface facing south, at three test sites: Cairo university (urban site), Tabbin institute (industrial site) and Alexandria (coastal site). The study was carried out over 12 month's period between May 2009 and May 2010. After exposure, corrosion products on the specimen surfaces were removed by dipping in Clarke's solution $\left(1 \mathrm{~L} \mathrm{HCl}+20 \mathrm{~g} \mathrm{Sb}_{2} \mathrm{O}_{3}+50 \mathrm{~g}\right.$ $\mathrm{SnCl}_{2}$ obtained from $\mathrm{El}$ Nasr Pharmaceutical Chemicals.co) at room temperature up to 25 minutes. After corrosion products removing, the specimens were rinsed with distilled water, dried with ablower, and then weighed to determine their weight loss. The weight loss in each test is the average obtained by using two samples. The climatic parameters influencing atmospheric corrosion were measured by Egyptian Environmental Affairs Agency and Tabbin Institute for metallurgical Studies (EEAA and TIMS), parameters measured during the exposure period. They are listed in Table 2. 
Table 1 Chemical analysis of carbon steel.

\begin{tabular}{|c|c|c|c|c|c|c|}
\hline Element & $\mathrm{Fe}$ & C & $\mathrm{Si}$ & $\mathbf{M n}$ & $\mathbf{P}$ & S \\
\hline $\begin{array}{c}\text { Composition } \\
\text { (wt. \%) }\end{array}$ & 99.43 & 0.06 & 0.07 & 0.4 & 0.028 & 0.011 \\
\hline
\end{tabular}

Table 2 Environmental conditions of exposure sites.

\begin{tabular}{|c|c|c|c|c|c|c|c|}
\hline $\begin{array}{l}\text { Test } \\
\text { site }\end{array}$ & $\begin{array}{l}\text { Enviro- } \\
\text { nment }\end{array}$ & $\begin{array}{l}\text { Ave- } \\
\text { rage } \\
\text { temp } \\
{ }^{\circ} \mathrm{C}\end{array}$ & $\begin{array}{l}\text { Aver } \\
\text {-age } \\
\text { rain } \\
\text { fall } \\
\mathrm{mm} / \\
\text { year }\end{array}$ & $\begin{array}{l}\text { Aver } \\
\text { a-ge } \\
\mathrm{RH}, \\
\%\end{array}$ & $\begin{array}{l}\text { Aver- } \\
\text { age } \\
\text { wind } \\
\text { speed } \\
\mathrm{m} / \mathrm{s}\end{array}$ & $\begin{array}{l}\mathrm{Cl}^{-} \\
\mathrm{mg} / \\
\mathrm{m}^{3}\end{array}$ & $\begin{array}{l}\mathrm{SO}_{2} \\
\mathrm{mg} / \\
\mathrm{m}^{3}\end{array}$ \\
\hline Alex & Coastal & $\begin{array}{l}21.41 \\
7 \\
\end{array}$ & 190 & $\begin{array}{l}69.2 \\
50 \\
\end{array}$ & 4 & $\begin{array}{l}2.26 \\
5 \\
\end{array}$ & $\underline{5}$ \\
\hline $\begin{array}{l}\text { El- } \\
\text { tabbi } \\
\text { n }\end{array}$ & $\begin{array}{l}\text { Industria } \\
1\end{array}$ & $\begin{array}{l}22.08 \\
3\end{array}$ & 26 & $\begin{array}{l}35.1 \\
67\end{array}$ & 3 & $\begin{array}{l}0.24 \\
0\end{array}$ & 38.923 \\
\hline $\begin{array}{l}\text { Cairo } \\
\text { uni }\end{array}$ & Urban & $\begin{array}{l}22.08 \\
3\end{array}$ & 26 & $\begin{array}{l}35.1 \\
67\end{array}$ & 3 & $\begin{array}{l}0.25 \\
5\end{array}$ & 24.438 \\
\hline
\end{tabular}

\section{Rust analysis}

\section{X-ray Diffraction (XRD)}

The test specimens, approximately $10 \times 10 \times 3 \mathrm{~mm}$ were subjected to atmospheric corrosion for 12 months at each site. One sample was taken from each site after 12 months exposure to investigate the rust analysis by XRD (conducted using a computer controlled D8ADVANCE $\mathrm{X}-\mathrm{R}$ diffractrometerGermany, employing CuK- $\alpha$ radiation).

\section{SEM/EDS}

Other coupons were used for SEM/EDS, after 12 months exposure. The corrosion products were characterized using scanning electron microscope (SEM)-type Inspect S50.

\section{Results and Discussion}

\section{Atmospheric corrosion rates as afunction of time}

Atmospheric corrosion penetration usually is not linear with time. The buildup of corrosion products often tends to reduce the corrosion rate. Pourpaix [14] utilized the so called linear the bilogarithmic law for atmospheric corrosion, to describe atmospheric corrosion damage as a function of time on a mathematical basis. According to the linear bilogarithmic law expressed by Eq. (1)

$$
\mathrm{P}=A \mathrm{t}^{\mathrm{B}} \text { or } \log \mathrm{P}=\mathrm{A}+\mathrm{B} \log \mathrm{t}
$$

Where $p$ is the corrosion penetration and $t$ is the exposure time. The corrosion penetration of carbon steel can be calculated from the weight loss measurements using equation (2).

$$
\mathrm{P}=\mathrm{W} / \mathrm{ad} \quad \text { (2) }
$$

Where $\mathrm{W}$ is the weight loss, in $\mathrm{g}$, a, is the surface area of the specimens, in $\mathrm{cm} 2$ and $\mathrm{d}$ is the density of carbon steel $(7.86 \mathrm{~g} / \mathrm{cm} 3)$. According to the linear bilogarithmic law, the atmospheric behavior of a specific material at a given location can be defined by the two parameters $\mathrm{A}$ and $\mathrm{B}$. The initial corrosion rate, observed during the first year of exposure, is described by $A$, while $B$ is a measure of the long term decrease in corrosion rate. When $B$ equals 0.5 , corrosion penetration increase is parabolic, with diffusion through the corrosion product layers as the rate controlling step. At B values appreciably smaller than 0.5 the corrosion products show protective, passivating characteristics. Higher B values, greater than 0.5 , are indicative of no protective corrosion products. An important aspect of the linear bilogarithmic law is that it facilitates the prediction of long term corrosion damage from short exposure tests. According to Pourbaix, this extrapolation is valid for up to 20 to 30 years. Table 3 shows the estimated values for $A, B$ and the correlation coefficient of the fitted curves shown in Fig. 1 for low carbon steel exposed at three sites. It is noted that in case of low carbon steel in urban and industrial stations (Cairo University and El-Tabbin sites), the values of B ( 0.52640 and 0.51228 respectively) correspond to a non-protective layer of rust, but it is close to the threshold that determines the protective behavior. In case of low carbon steel in the Alexandria station (coastal site) the value of $B(0.89830)$ is close to 1 , indicating that the rust layer had a linear growth and therefore the corrosion products were not sufficiently protective.

Table 3 Values of initial corrosion rate observed during the first year of exposure " $A$ ", long term decrease in corrosion rate " $B$ " and correlation

\begin{tabular}{|c|c|c|c|}
\hline \multirow{2}{*}{ Test site } & \multirow[b]{2}{*}{ A } & \multirow[b]{2}{*}{$\mathrm{B}$} & \multirow[b]{2}{*}{$\mathrm{R} 2$} \\
\hline & & & \\
\hline Alexandria & 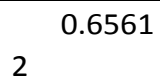 & 0.8983 & 0.9791 \\
\hline El-tabbin & $\begin{array}{ll} & 1.1199 \\
0 & \\
\end{array}$ & 0.5123 & 0.9364 \\
\hline $\begin{array}{l}\text { Cairo } \\
\text { University }\end{array}$ & $2^{1.0357}$ & 0.5264 & 10.9034 \\
\hline
\end{tabular}
coefficient of the fitted curves"R2".

As can be observed from Figure 1 the corrosion penetration increased in the first 4 months in the order of El - Tabbin (1.52652)> Cairo University (1.4118)>Alexandria(1.20143).This behaviorseems to be related to thecontent of $\mathrm{SO} 2$ at the industrial station.

\section{Rust Analysis}

\section{XRD}

Figure 2 shows XRD spectra of corrosion products of carbon steel obtained after anexposure time 12months. In case of Cairo University station (urban site) and El-Tabbin station (industrial site), the phases detected were mainly $\gamma$-FeOOH, $\alpha-\mathrm{FeOOH}$ and $\mathrm{Fe} 3 \mathrm{O} 4$. In case of samples taken from Alexandria station (coastal site), only $\beta-\mathrm{FeOOH}$ and $\mathrm{Fe} 3 \mathrm{O} 4$ phases, were detected.

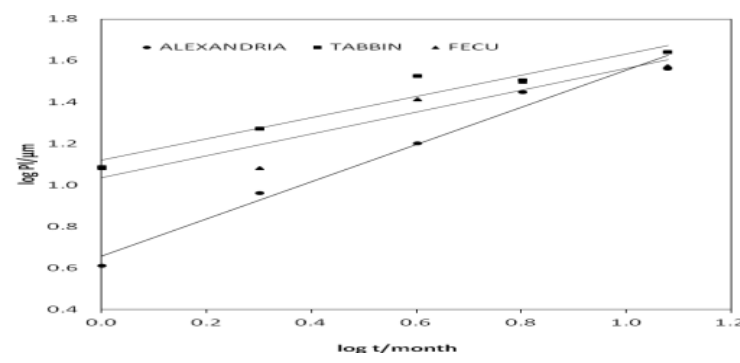

Figure 1 Corrosion penetration of carbon steel in different environments as a function of time. 
irregular shape which exhibits horizontal and longitudinal cracking.

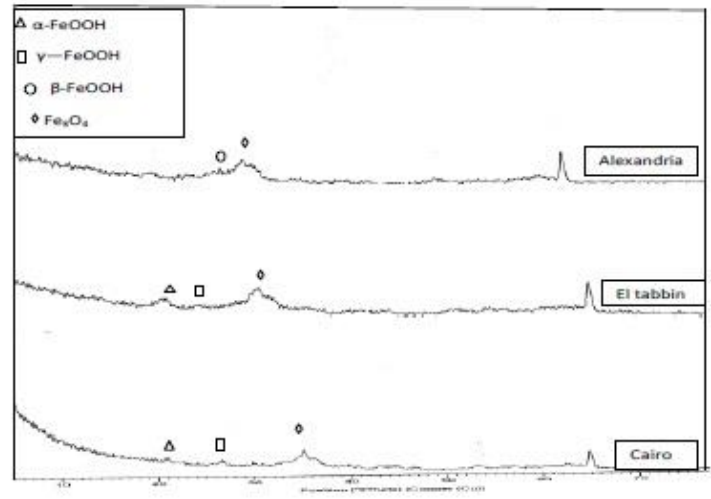

Figure 2 XRD obtained after 12-month (El-Tabbin) Industrial area, (Cairo University).

In the specimen exposed at El-Tabbin station (industrial site), (flowery structure) typical of lepidocrocite and globular (cotton balls) typical of goethite were found as shown in (Fig.4-a). (Fig. 4-b) depicts a cross - section of carbon steel specimen exposed at El-Tabbin, it shows an irregular layer of corrosion products which exhibits horizontal and longitudinal cracking. In the specimen exposed at ElTabbin station (industrial site), (flowery structure) typical of lepidocrocite and globular (cotton balls) typical of goethite were found as shown in (Fig.4-a).

(Fig. 4-b) depicts a cross - section of carbon steel specimen exposed at El-Tabbin, it shows an irregular layer of corrosion products which exhibits horizontal and longitudinal cracking. According to Table 2, air analysis of the industrial (El- Tabbin site) as well as urban (Cairo site) was characterized by high $\mathrm{SO} 2$ content ( 38.923 and $24.438 \mathrm{mg} / \mathrm{m3}$, respectively). In atmospheres polluted by $\mathrm{SO} 2$, however, the surface of electrolyte is usually mildly acidic and $\mathrm{Fe}(\mathrm{OH}) 2$ does not precipitate[15].

Hiller [16] considers $\gamma$-FeOOH as the primary crystalline corrosion product. In mildly acidic solutions $\gamma$-FeOOH is transformed into $\alpha$ - $\mathrm{FeOOH}$ in a process that is dependent on the sulphate concentration and temperature. $\alpha$ - FeOOH seems to be the most stable modification of ferric oxide hydroxides. The solubility of $\alpha$ - FeOOH is approximately 105 times lower than that of $y$-FeOOH [17].

According to the kinetic study in industrial and urban atmospheres, the rust layer formed on carbon steel correspond to a non-protective layer of rust, but it is close to the threshold that determines the protective behavior. The XRD and SEM analyses confirm the relatively protective character of this rust layer in an atmosphere which is relatively dry and slightly rich in SO2. However, when the climate is usually humid or rainy, this effect is reduced.

Figure (5-a) shows cigar-shaped crystals of akaganite found in the specimen exposed at Alexandria station (coastal site). (Fig.5-b) shows the cross section area in the specimen exposed at Alexandria station (coastal site); a thin layer of
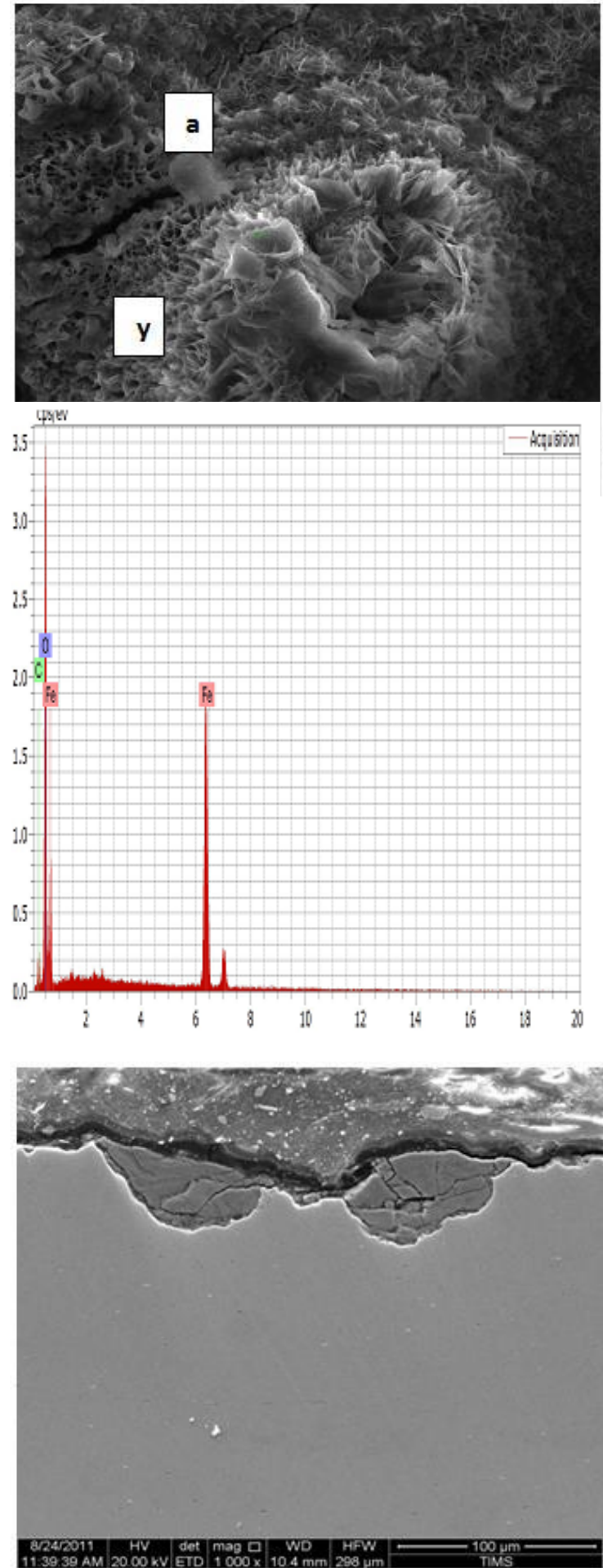

Figure 3 Morphology of corrosion products in case of urban area (Cairo University).

(Figure 5-c) shows mapping of chlorine through the cross section area in the specimen exposed at Alexandria station (coastal site); uniform distribution of chlorine ions. In Alexandria (marine atmosphere), the surface of electrolyte contains chlorides, $\beta$ - 


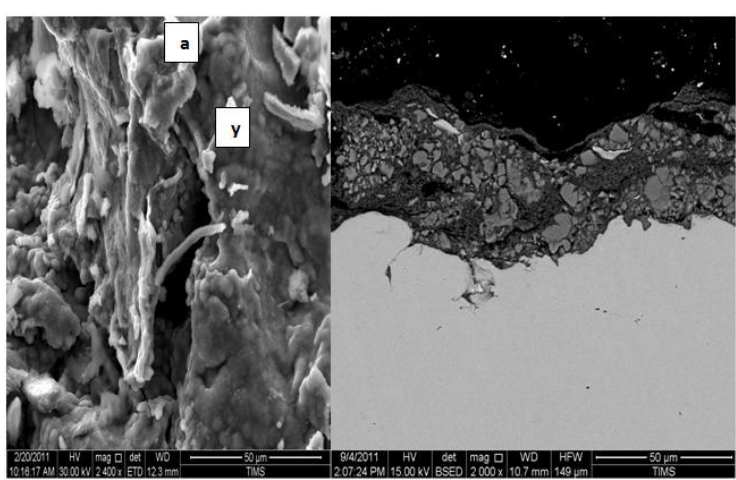

$\mathrm{FeOOH}$ is found which is in accorde with the findings of Keller [18].

Figure 4 Morphology of corrosion products in case of industrial area (El-Tabbin).
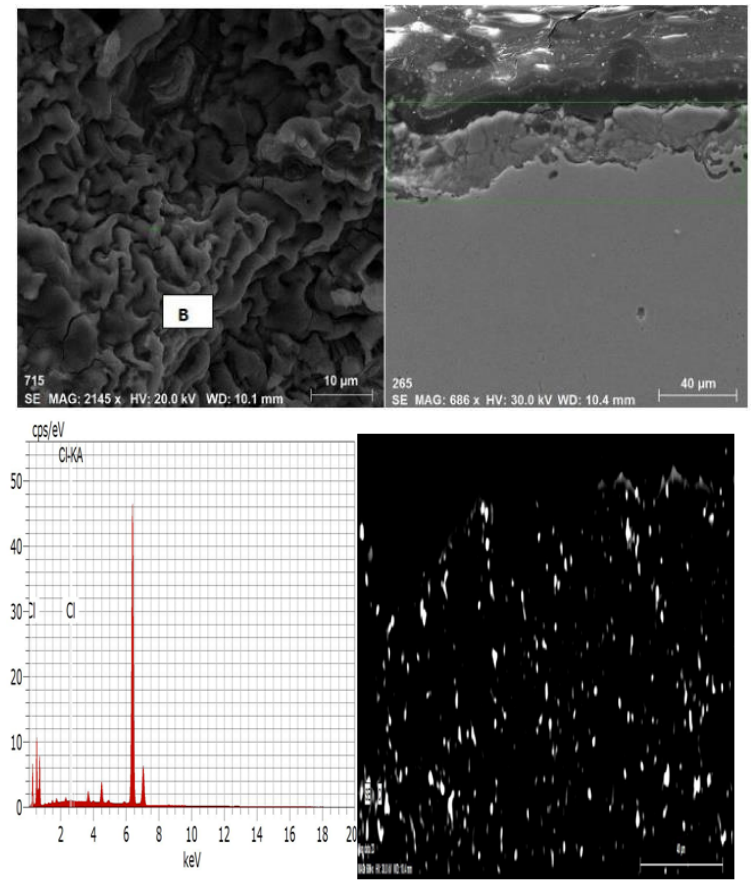

Figure 5 Morphology of corrosion products in case of coastal area (Alexandria).

The tormation of detectable amounts of $\beta \mathrm{FeOOH}$ on freely exposed steel surfaces seems to require high yearly average chloride deposition rates. However on rain protected steel surfaces, $\beta$ - FeOOH was found to be abundant in rust also when the chloride deposition rates were as low as $40 \mathrm{mg} / \mathrm{m} 2 /$ day [19]. Magnetite is also formed as one of the main constituents. Magnetite may form by oxidation of $\mathrm{Fe}(\mathrm{OH}) 2$ or intermediate ferrous -ferric species such as green rust [20]. It may also be formed by reduction of $\mathrm{FeOOH}$ in the presence of limited oxygen supply [21] according to;

$$
8 \mathrm{FeOOH}+\mathrm{Fe} \mathrm{Fe}_{3} \mathrm{O}_{4}+4 \mathrm{H}_{2} \mathrm{O}
$$

Magnetite is usually detected in the inner part of rust adhering to the steel surface of specimens that have been subjected to prolonged exposure, where oxygen depletion may occur [22-23]. From the kinetic results the rust layer had a linear growth and therefore the corrosion products were not sufficiently protective. This is confirmed by the SEM analysis which shows the non-protective character of this rust layer in an atmosphere slightly rich in chlorine. In all cases, a good correlation was found between the protective characteristics of rust calculated from mass loss data and observations made by SEM and XRD.

\section{Conclusions}

- The carbon steel showed good atmospheric corrosion resistance especially at industrial and urban sites.

- The corrosion behavior of the carbon steel tested in three different environments is kinetically well represented by linear the bilogarithmic law for atmospheric corrosion.

- Rust layer on carbon steel formed in case of in industrial as well as urban areas was composed of mono layer. The main phases detected were $\gamma$ $\mathrm{FeOOH}, \alpha-\mathrm{FeOOH}$ and $\mathrm{Fe} 3 \mathrm{O} 4$.

- In case of coastal area, samples were covered by a discontinuous corrosion product layer of low compactness. This layer was mainly composed of $\beta$ $\mathrm{FeOOH}$ and $\mathrm{Fe}_{3} \mathrm{O}_{4}$ phases.

\section{References}

[1] C. Leygraf, T.E. Graedel, Atmospheric Corrosion, John Wiley and Sons, New York,2000.

[2] P.A. Schweitzer, Atmospheric Degradation and Corrosion Control, Marcel Dekker, New York, 1999.

[3] V. Kucera, E. Mattson, Atmospheric Corrosion, in: F, Mansfeld (Ed.), Corrosion Mechanisms, Marcel Dekker, New York, 1987, 211-284.

[4] S.Oesch, The effect of SO2, NO2, NO and $\mathrm{O} 3$ on the corrosion of unalloyed carbon steel and weathering steel-the results of laboratory exposures, Corr. Sci. 38(1996) 1357-1368.

[5] T. Nakanishi, Y. Masuda, K. Koumoto, Deposition of $Y$ $\mathrm{FeOOH}, \mathrm{Fe} 304$, and Fe on Pd-Catalyzcd Substrates, Journal of Crystal Growth, 284(2005), 176.

[6] Ph. Refait, J-B. Mernet, C. Bon et al., Formation of the Fe (П)-Fe (П।) hydroxyl sulphate Green Rust during Marine Corrosion of Steel, Corrosion Science. 45 (2003), 833.

[7] P. Dillmann, R. Balasubramaniam, G. Beranger, Characterization of Protective Rust on Ancient Indian Iron Using Microprobe Analyses, Corrosion Science. 44 (2002) 2231.

[8] OLA de Faria, S. Venancio Silva, MT.de Oliveira, Raman Microspectroscopy of Some Iron oxides and Oxyhydroxides, Journal of Raman Spectroscopy, 28CID (1998) 873.

[9] M. Yamashita, T. Mishawa, Advances in understanding atmospheric corrosion of iron, Corros. Eng. 49 (2000) 159.

[10] Ph. Dillmann, F. Mazandier, S. Hoerle, Advances in understanding atmospheric corrosion of iron. I. rust characterization of ancient ferrous arte facts exposed to indoor atmospheric corrosion, Corros. Sci.46 (2004) 1401.

[11] T. Misawa, K. Hashimoto, S.Shimodaira, The mechanism of formation of iron oxides and oxyhydroxides in aqueous solutions at room temperature, Corr. Sci. 14(1974) 131-149.

[12] M.Sratmann, K. Bohnenkamp, W.J. Engell, An study of phase-transition in rust layers, Corr. Sci. 23(1983) 969985. 
[13] ASTM G 50-10, Standard Practice for Conducting Atmospheric Corrosion Tests on Metals", Book of Standards Volume: 03.02, ASTM International, 2010.

[14] M. Pourbaix, "The linear bilogarithmic law for atmospheric corrosion, in Ailor, W.H. (ed.), Atmospheric Corrosion, New York, John Wiley and Sons, 1982, 107121.

[15] V. Kucera and E. Mattsson, Atmospheric Corrosion, In: Corrosion Mechanims, F. Mansfeld (Ed.), New York, 1987, 211-284.

[16] J.E. Hiller, Werkst. Korros. 17 (1966) 943-951.

[17] T. Misawa, The thermodynamic consideration for Fe$\mathrm{H} 2 \mathrm{O}$ system at $250 \mathrm{C}$, the thermodynamic Corros. Sci. 13 (1973) 659-676.

[18] P. Keller, Occurrence, formation and phase transformation of $\beta-\mathrm{FeOOH}$ in Roast, Werkst. Korros. 20 (1969) 102-108.

[19] T. Misawa, T. Kyuno, W. Suëtaka and S. Shimodaira, The mechanism of atmospheric rusting and the effect of $\mathrm{Cu}$ and $\mathrm{P}$ on the rust formation of low alloy steel, Corros. Sci.11 (1971) 35-48.

[20] H. Schwarz, The effect of magnetite rusting and under rusting of paint coats, Werkst. Korros. 23 (1972) 48- 663.

[21] A.K. Singh, T. Ericsson and L. Häggström, Mossbauer and X-ray diffraction phase analysis of rusts from atmospheric test sites with different environments in Sweden, Corros. Sci. 25 (1985) 931945. 